\title{
Experimental 3D Printed 4-Port Ventilator Manifold for Potential Use in Disaster Surges
}

\author{
Richard Siderits ${ }^{1}$, Gregory Neyman² \\ ${ }^{1}$ Robert Wood Johnson Medical School, New Brunswick, USA \\ ${ }^{2}$ Robert Wood Johnson University Hospital, Hamilton, USA \\ Email: rsiderit@rwjuhh.edu
}

Received 12 June 2014; revised 7 July 2014; accepted 21 August 2014

Copyright $@ 2014$ by authors and Scientific Research Publishing Inc.

This work is licensed under the Creative Commons Attribution International License (CC BY). http://creativecommons.org/licenses/by/4.0/

(c) (i)

\begin{abstract}
We describe the design, modeling and production of a 3D printed manifold for attaching multiple respiration masks to a single ventilator machine. During a disaster surge this would allow up to four masks to be connected to a single ventilator source. In a disaster which involves high numbers of patients with lung damage, simultaneous respirator support may be required; however, the number of patients may quickly outnumber the available respirator machines. We explore the use of a rapid and low cost 3D printing method referred to as Fused Filament Deposition (FFD) for creation of a four-port ventilator manifold. This 3D printing method deposits layers of melted ABS plastic filament in a fine "stream" onto successive layers in order to form a three dimensional object. The standard file format for this object (manifold attachment) can be made globally available through the internet. It can be "printed" anywhere and anytime it is needed as a three dimensional object at extremely low cost (under two dollars per unit) and since the digital file that represents the object is modifiable, "derivative" versions can be redesigned to suit a broad range of potential applications, especially in areas with limited healthcare resources.
\end{abstract}

\section{Keywords}

3D, Printing, Manifold, Respirator, Fused Filament Deposition

\section{Introduction}

It has been experimentally shown in both artificial lung and in an animal model that a single ventilator could, in the event of a disaster surge, be modified to ventilate four simulated adults for a limited time [1] [2]. In this paper we used a freely downloadable Computer Assisted Design (CAD) program called TrueSpace to create a Three Dimensional (3D) model of a four port Ventilator-Respirator Manifold [3] [4]. 
The design process used simple objects within the program such as a cube and cylinders to either add to or subtract from each other to form the desired shape, size and configuration of a four port manifold. The ports were each given a 0.5 degree taper from the base to the end of the port. The ends of the designed ports were measured against both respirator mask tubing and the existing machine port dimensions. The resulting 3D model was then saved as a StereoLithography (STL) file format to be sent to a low cost 3D printer. The file that described the manifold was checked for surface integrity in second freely downloadable program called Netfabb [4]. Once the file had been checked for "water tightness" of the surfaces that describe the surface layers, it was sent to an Up!3D printer [5]. This printer melted a filament of Acrylonitrile butadiene styrene (ABS) plastic at 260 degrees Fahrenheit. The 3D printer was set to normal resolution, see Figure 1.

\section{Result}

The manifold was printed standing upright (see Figure 1. Lower Left) to minimize the amount of "support" material that would need to be removed after printing.

The model, as designed in TrueSpace CAD program is represented by 7232 facets using 3766 vertices. Its overall dimensions are $4.17 \times 7.32 \times 7.90 \mathrm{~cm}$. It is printed on an Up!3D Afina model printer in ABS plastic at 200 micron (extruded width) from a $1.75 \mathrm{~mm}$ spool. Build parameters are set as follows:

Resolution-Normal; Heat platform-No; Z resolution $=0.2 \mathrm{~mm}$; Base height $=2.0 \mathrm{~mm}$; Surface thickness $=4$ layers with 25\% inner fill and Support set to 2 layers (Space 8 lines Area $15 \mathrm{~mm}^{2}$, Angle 45 degrees). The model is created in 405 layers and required 4:59 (hours: minutes) to complete while using 61.4 grams of ABS plastic at a cost of less than two dollars (based on average retail cost of $1 \mathrm{KG}$ of ABS plastic filament).

The printed object showed uniform surface thickness, high rigidity and high tensile strength with accurate final measurements (as compared to the design measurements and CAD representation) without appreciable shrinkage during or after the cooling process. The "fit" test is seen in Figure 2. Both the manifold ventilator nozzle and individual ports fit snugly, without leakage (see Figure 2).

\section{Discussion}

3D printing has been described as a "transformative" technology in society [6]. We are recognizing the remarkable potential for this technology throughout healthcare [7]. The scope of 3D printing is broad and includes Bioprinting as well as medical devices [8]. We have already seen the early applications of 3D printed splints and casts and are quickly moving toward 3D printed real time automated wound management systems. This paper shows that it is possible to design a 3D print as many low cost four-port ventilator manifolds, as needed, in the

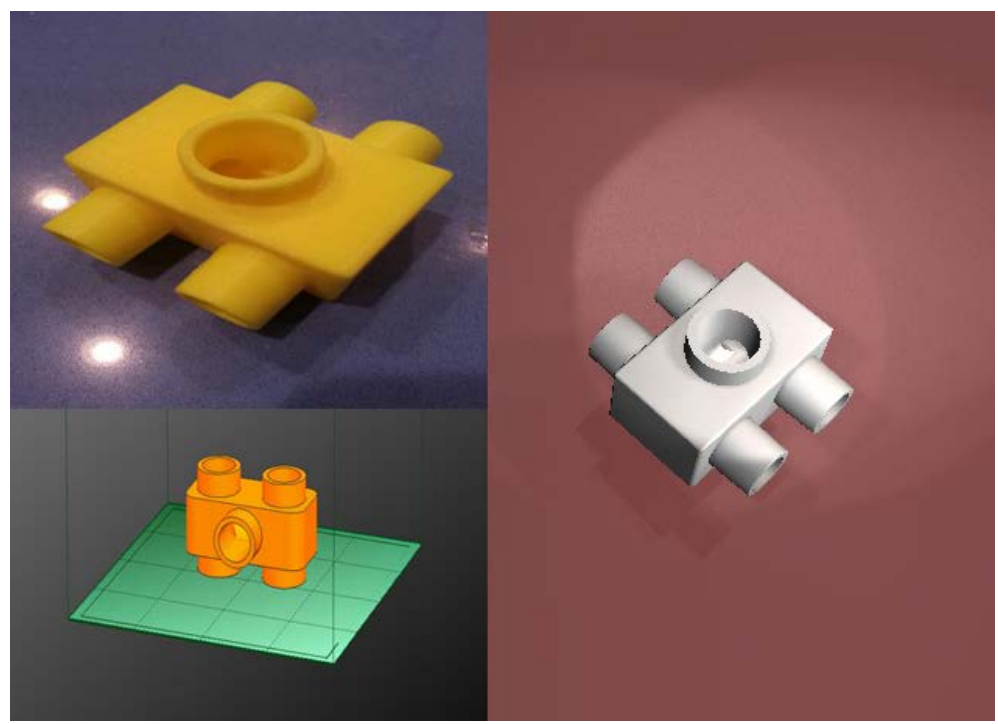

Figure 1. Top left shows 3D printed part in ABS plastic; Left bottom Up!3D software with part loaded and ready to print; Right panel shows CAD rendering of the Manifold available for modification as a DXF or STL formatted file. 


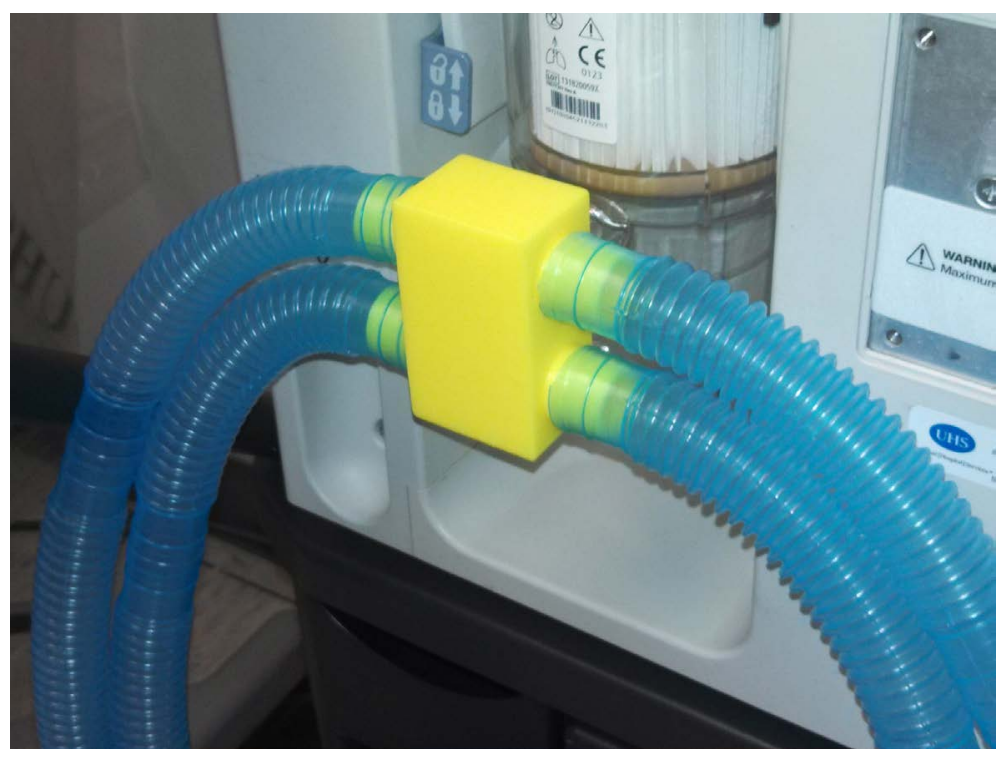

Figure 2. "Fit" Test of 4-port manifold on Ventilator.

event of a disaster surge involving patients with pulmonary damage. The digital files for the manifold can be freely shared over the internet on websites such as "Thingiverse", assuring availability in areas or services with limited healthcare resources [9]. The file can be modified in any one of dozen free CAD programs, thereby increasing the likelihood of shortened product development and increased use of derivative versions [10].

\section{References}

[1] Neyman, G. and Irvin, C.B. (2006) A Single Ventilator for Multiple Simulated Patients to Meet Disaster Surge. Academic Emergency Medicine, 13, 1246-1249.

[2] Paladino, L., Silverberg, M., Charchaflieh, J.G., et al. (2008) Increasing Ventilator Surge Capacity in Disasters: Ventilation of Four Adult-Human-Sized Sheep on a Single Ventilator with a Modified Circuit. Resuscitation, 77, 121-126. http://dx.doi.org/10.1016/..resuscitation.2007.10.016

[3] TrueSpace-3D Modeling Software (Accessed December 16, 2013). http://caligari.us/

[4] Netfabb Software-Software for 3D Printing-3D Software for STL Files-Fixing, Repair, Editing, Merge STL Data for Rapid Manufacturing-STL Viewers and STL Repair. (Accessed December 16, 2013) http://www.netfabb.com/

[5] Personal Portable 3D Printer. (Accessed December 16, 2013) http://www.pp3dp.com/

[6] Anderson, C. (2012) Makers: The New Industrial Revolution. Crown Business, New York.

[7] Lipson, H. (2013) Fabricated: The New World of 3D Printing. John Wiley and Sons, Indianapolis.

[8] Drexler, K.E. (2013) Radical Abundance: How a Revolution in Nanotechnology Will Change Civilization. PublicAffairs, New York.

[9] Thingiverse-Digital Designs for Physical Objects. (Accessed November 15, 2013) http://www.thingiverse.com/

[10] (2013) MGI Disruptive Technologies Full Report.

http://www.mckinsey.com/ /media/McKinsey/dotcom/Insights\%20and\%20pubs/MGI/Research/Technology\%20and\% 20Innovation/Disruptive\%20technologies/MGI_Disruptive_technologies_Full_report_May2013.ashx 
Scientific Research Publishing (SCIRP) is one of the largest Open Access journal publishers. It is currently publishing more than 200 open access, online, peer-reviewed journals covering a wide range of academic disciplines. SCIRP serves the worldwide academic communities and contributes to the progress and application of science with its publication.

Other selected journals from SCIRP are listed as below. Submit your manuscript to us via either submit@scirp.org or Online Submission Portal.
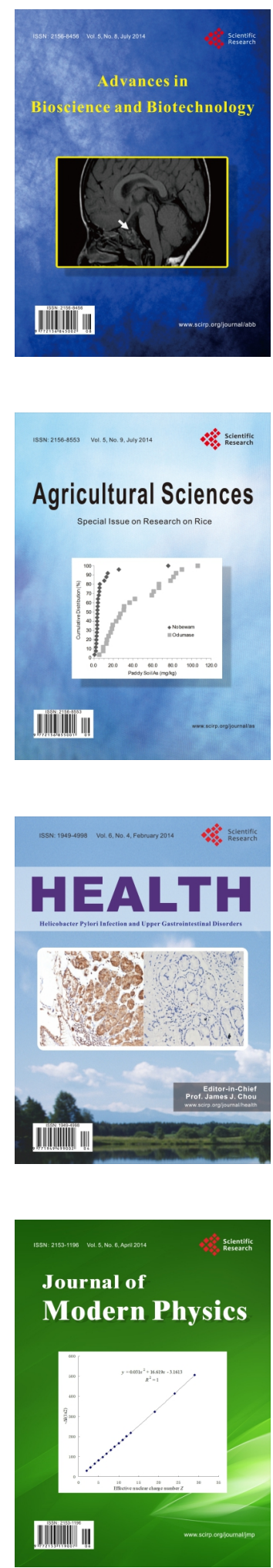
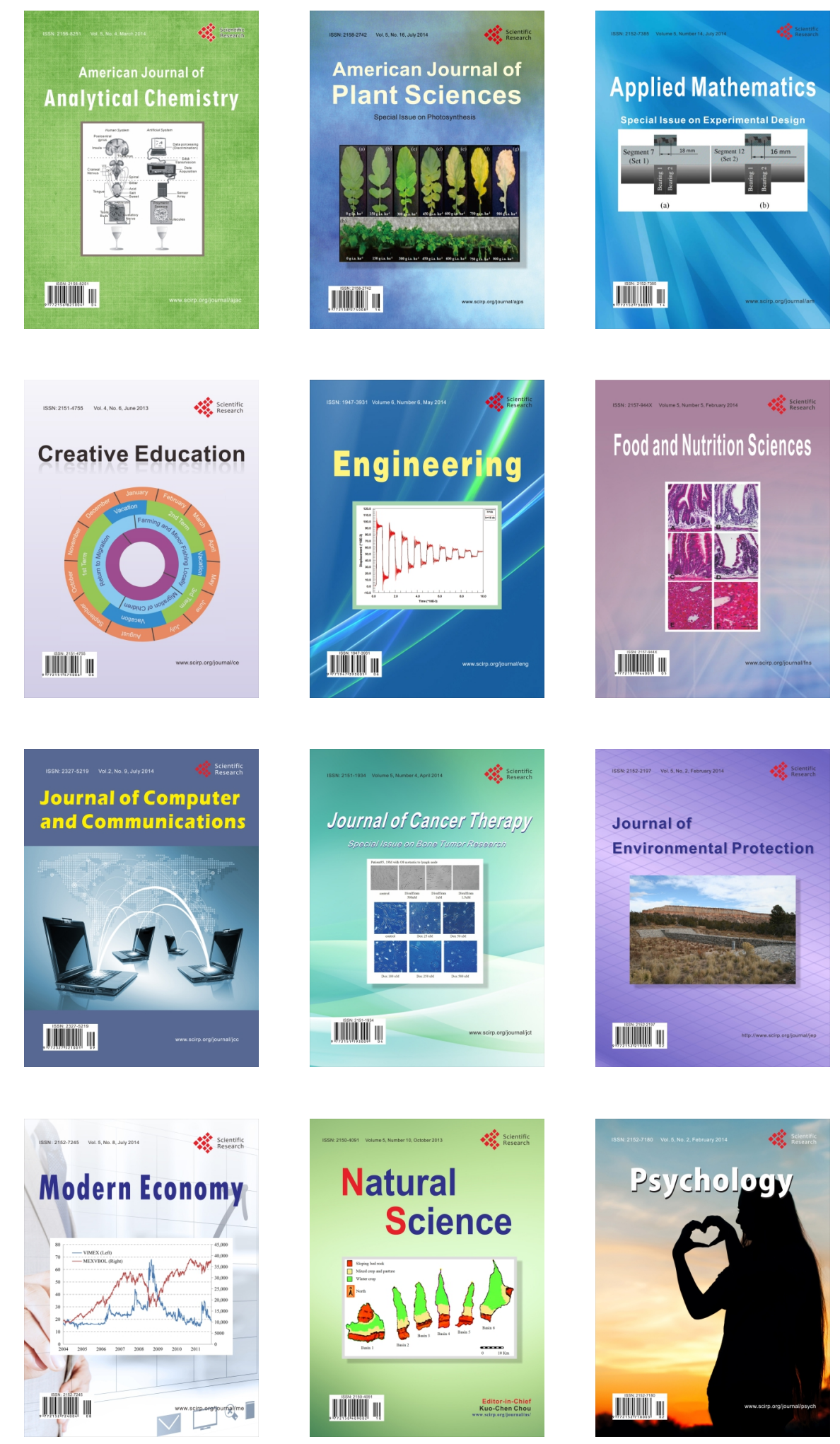